\title{
PERSPECTIVES
}

\section{Promoting the learning of immunology in developing countries}

\author{
Jean-Jacques Fournié, Frédérique Gaits and Marc Bonneville
}

Abstract | In 2005, the economic gap

between developing and developed

countries is bigger than ever, and this

has consequences for public health. So,

to sustain education and research in the most resource-constrained regions, it is necessary to promote local teaching of the immunology of infectious diseases. This Perspective article reviews the use and expected efficiency of current Internet-based tools for higher education in the biomedical sciences in developing countries. We also discuss other approaches to improve access to updated training in immunology for students in the poorest countries.

It is difficult to assess and compare the way of life from one country to another. However, in 1990, the United Nations Development Programme created an indicator of human development (HDI) for this purpose. This indicator integrates life expectancy at birth, rate of education and income per head, and the values range from 0 (the lowest possible quality of life) to 1 (the highest possible quality of life). By 2003, this value was greater than 0.92 in the United Kingdom, France and Switzerland but less than 0.5 in 30 African countries ${ }^{1}$, indicating that the life expectancy of someone in one of these African countries is approximately half of that of someone from the United Kingdom, France or Switzerland. These numbers also illustrate that economic inequality correlates strongly with deficits in teaching and in public health (FIG. 1). For example, the number of individuals with infectious diseases such as tuberculosis, malaria and AIDS is highest in the countries with the lowest HDI values ${ }^{2}$. The occurrence of these infectious diseases in the same geographical regions leads to the appearance of synergistic co-infections, such as those seen with Mycobacterium tuberculosis and HIV. Indeed, according to Mireille C. Dosso, who is the scientific adviser of the Minister of Health and Population and the Director of the Pasteur Institute in Abidjan, Côte d'Ivoire, "Most of the numerous infectious diseases we see daily in our practice appear as complex secondary infections barely described in textbooks" (M. C. Dosso, personal communication). This Perspective article discusses the need to promote the learning of immunology in developing countries both by direct interactions between individuals and by online learning (also known as e-learning). We focus on Africa because, during the past 30 years, this continent has endured a calamitous health situation, combined with extreme poverty, malnutrition and illiteracy.

\section{Investing for the future}

In industrialized countries, the high standard of living is linked to a sustained high level of economic resources, which allow a constant increase in investment in teaching, research and technology. This has been accompanied by an increasing focus on the health problems of the developed world, which is exemplified by recent increases in research grants for the study of cardiovascular diseases, diabetes and cancer (all diseases of the developed world). As a result of these large investments in biomedical research and drug development, production of scientific knowledge is now concentrated in these countries. Although this attracts the best students from abroad, in particular from countries of the developing world, this increasingly expensive technological evolution yields costly products (including antiviral drugs, therapeutic monoclonal antibodies and automated technical instruments) that become less and less available to developing countries and that are eventually unsuited to the local needs of these countries. How many universities in Burkina Faso or Pakistan can afford to purchase many online subscriptions to scientific journals at an annual cost of US\$500-1500 each? How many flow cytometers are found in biomedical laboratories in Peru or Thailand, despite the huge clinical need for these machines? How many universities in developing countries can purchase the licenses for the software that is installed on each computer?

So, although we celebrate the genomic revolution in life sciences and the explosion of biotechnologies, paradoxically we simultaneously witness the expansion of public-health problems in the developing world. These include the appearance of bacterial or viral infections that are resistant to available treatments, the emergence of diseases such as Creutzfeldt-Jakob disease and severe acute respiratory syndrome (SARS), and the increasing need for better vaccines against infection with the causative agents of tuberculosis, meningitis and AIDS. This paradox originates from the lack of interest of developed countries in the problems of the developing world, the sparse scientific and medical teaching exchanges that are aimed at development of these regions, and the scarcity of 


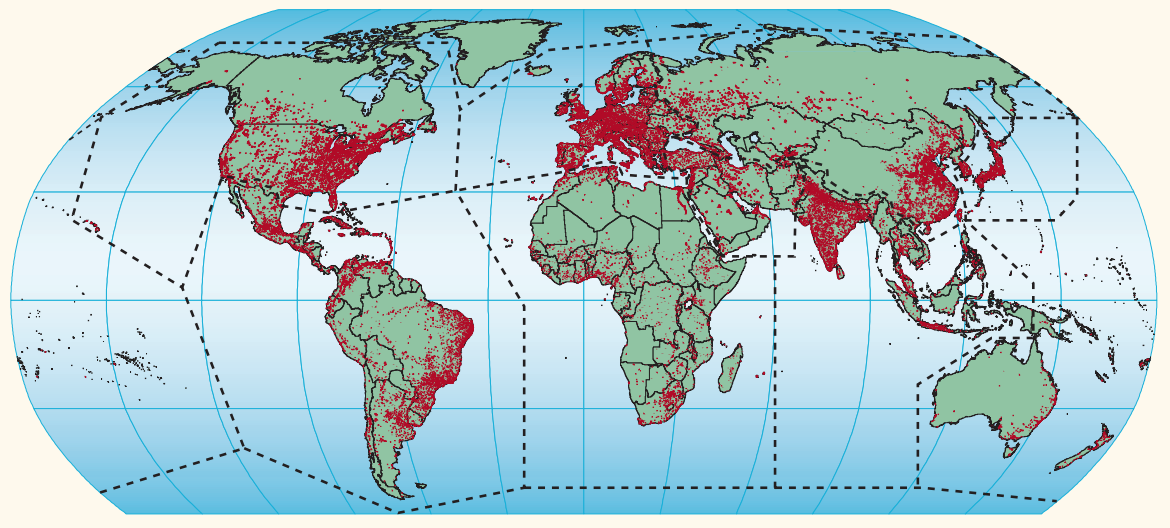

\begin{tabular}{|c|c|c|c|}
\hline Region* & $\begin{array}{l}\text { Number of } \\
\text { inhabitants } \\
\text { in } 2003\left(\times 10^{6}\right)\end{array}$ & $\begin{array}{l}\text { Number of universities } \\
\text { and colleges per } \\
10^{7} \text { inhabitants }\end{array}$ & $\begin{array}{l}\text { Recorded cases of } \\
\text { HIV, TB and malaria } \\
\text { per } 10^{5} \text { inhabitants }\end{array}$ \\
\hline North America & 317 & 65 & 317 \\
\hline Europe & 523 & 30 & 149 \\
\hline Asia & 1632 & 4 & $250 \ddagger$ \\
\hline Far East & 174 & 40 & 59 \\
\hline $\begin{array}{l}\text { Latin America } \\
\text { and Caribbean }\end{array}$ & 522 & 16 & 641 \\
\hline Africa & 813 & 3 & 7723 \\
\hline Middle East & 404 & 9 & 601 \\
\hline Southeast Asia & 1735 & 3 & 731 \\
\hline Oceania & 31 & 29 & $700^{\S}$ \\
\hline
\end{tabular}

Figure 1 | Global distribution of universities and infectious diseases in 2003. We arbitrarily divided the world into nine zones (dashed lines), which are shown on a grid map that indicates current country borders (black lines) and cities of more than 5000 inhabitants (red dots) ${ }^{10}$. The data were calculated from the updated statistics obtained for 230 countries. Data include the absolute number of inhabitants in 2003 expressed in millions (data obtained from REF. 10), the number of universities and colleges per 10 million inhabitants (data obtained from Universities Worldwide, the International Association of Universities, the Braintrack University Index and United Nations Educational, Scientific and Cultural Organization (UNESCO); see the Online links box), and the cumulative number of cases of HIV/AIDS, tuberculosis (TB) and malaria per 0.1 million inhabitants (data obtained from the Joint United Nations Programme on HIV/AIDS and from the World Health Organization Global Atlas of Infectious Diseases; see the Online links box). This figure is modified, with permission, from REF. 11 @ (2005) Center for International Earth Science Information Network, Columbia University. *Regions match those indicated by dashed lines on map. 得nderestimated because cases of HIV infection are largely under-reported in China (data obtained from AVERT; see the Online links box). \$Malaria occurred only in Papua New Guinea and the Solomon Islands. None of the other 21 countries in this zone had any recorded cases of malaria.

locally based research programmes in the developing world. Nevertheless, the recent global awareness of the extent of epidemics of tuberculosis, malaria, AIDS and SARS has induced an explosion of immunological research, both in developed and developing countries. However, as discussed later, it is important to support local research and teaching structures in developing countries. Among other requirements, the poorest countries need help to ensure adequate training for local researchers and doctors, using local tools and focused on topics that are directly relevant to local public-health problems. In addition, providing local training for specialized staff, in well-equipped laboratories and under the tuition of politically and financially stable research institutions, should promote durable research efforts in developing countries, and this is necessary to stop the migration of top students to laboratories in the developed world. By providing reasonable funding, it should be possible to initiate the cascade knowledge $\rightarrow$ technology $\rightarrow$ development $\rightarrow$ knowledge. For example, the development of engineering sciences at the Kigali Institute of Science, Technology and Management, in Kigali, Rwanda, is a remarkable example of how successful teaching and economic support can foster the establishment of an institute that provides high-quality teaching and transfer of technology to the country ${ }^{3}$.

\section{Infectious diseases are a priority}

Among the priorities of higher education in developing countries, medical sciences and, notably, infectious diseases occupy a growing place next to agronomy and engineering. For practical or historical reasons, the teaching programmes that specialize in infectious diseases link immunology to microbiology, virology, genetics or biochemistry. Teaching and research are often linked, either in university research projects or in research institutes that offer undergraduate and postgraduate programmes. Although many of these programmes focus on the widespread problems of HIV/AIDS, tuberculosis and malaria, the main topics that are taught vary between countries, often being targeted at the tropical diseases that are endemic to that region. For example, the Armauer Hansen Research Institute, in Addis Ababa, Ethiopia, is an important centre for studying leprosy; Buruli ulcer, a disease caused by infection with Mycobacterium ulcerans, is studied at the Pasteur Institute in Abidjan, Côte d'Ivoire; and the Oswaldo Cruz Institute, in Rio de Janeiro, Brazil, is one of the leading research centres in the world for studies on Trypanosoma cruzi (see the Online links box). Other initiatives, such as the Centre for HIV/AIDS Networking (HIVAN; see the Online links box), in Durban, South Africa, aim to promote a multi-subject approach to questions that are related to HIV: HIVAN does this by distributing information for teachers, researchers, doctors and patients by means of local forums, a web site and bilingual newsletters in Zulu and English, and by directly supporting local research laboratories.

Despite these efforts, unfortunately, immunology remains an under-represented science in terms of the number of countries where teaching is available. As has recently been reviewed ${ }^{4}$, several African countries, including Botswana, Guinea, Lesotho and Swaziland, have universities that do not teach immunology. Also, there are only a few African universities, such as Kenyatta University (Kenyatta, Kenya), the University of Cape Town (Cape Town, South Africa) and the University of Khartoum (Khartoum, Sudan), that have specific courses in immunology that lead to the award of a certificate. Most other African universities offer lessons in basic immunology and have 1-5-week workshops teaching immunology and vaccinology. These are aimed at doctors, teachers, scientists and undergraduate students, are organized by local authorities and are carried out under the joint supervision of internal and external experts. As a 
consequence, both the content and the level to which immunology courses are taught differ considerably from one country to another. Assuming that the African example also applies to other developing continents, at present, the teaching and research in these regions are insufficient to meet the needs of the developing world, leading to the need for a globalized and cost-effective promotion of immunology learning in these countries.

\section{Internet help: concepts and realities}

One of the main problems that faces the teaching of immunology in universities in developing countries is the growing number of students and the need for these students to have access to the appropriate media support. Specialized books, CDs and international journals are either unavailable or outdated in many of the universities, which have a limited income. This highlights a role for dedicated international institutions such as the World Bank, the United Nations Educational, Scientific and Cultural Organization (UNESCO) and the World Health Organization (WHO) (see the Online links box) to enable these universities to access material for biomedical learning. This could be done at low cost by providing universities either with dedicated hardware and updated online subscriptions (including installing networks, with a server and some computers) or, when such hardware is already available, with suitable software and subscriptions.

This was the goal of the recent Health InterNetwork Access to Research Initiative (HINARI; see the Online links box), which was launched in January 2002 by the WHO and six publishers of biomedical journals (Blackwell Publishing, Elsevier Science, Harcourt Worldwide Scientific, Technical and Medical Group, Wolters Kluwer International Health \& Science, Springer, and John Wiley \& Sons). These have now been joined by many other publishers, and the initiative provides non-profit research institutions with free, or very low cost, Internet access to numerous scientific publications for several years. HINARI therefore recently opened online access for universities, institutes for health and medical research, medical and pharmacy schools, and medical libraries, as well as university and hospital libraries, in many developing countries. This operation, which aimed to reduce the 'e-gap' between rich and poor countries, also acknowledges the power of the Internet as an instrument of mass communication.
The Dean of The University of Dar Es Salaam (Dar Es Salaam, Tanzania), I. H. Jumaa, recently acknowledged the benefits of online courses at a conference on the successful reforms of teaching, entitled African Universities that Function ${ }^{3}$. This Internet-based teaching, in which a professor uses the Internet to communicate with students, allows large numbers of students to access lessons simultaneously, to take tests, to submit homework and reports for review, and to participate in online discussion forums. Despite the loss of direct contact with the teacher, the Internet provides a solution for teaching in developing countries. This "divine media" allows teachers, at low cost, to contact many pupils instantly and simultaneously, to be assessed by peers, to update lesson content at any time and to draw from the huge reservoir of available online data. E. N. Sibanda, an immunologist at the University of Zimbabwe (Harare, Zimbabwe), sees the Internet as the most cost-effective mechanism of communication for promoting virtual lessons in immunology on the African continent, but he recognizes that its limitations mean that the teaching of practical classes is impossible 4 . This view is shared by economist G. Winter, who recommends the establishment of Internet networks of collective expertise that link scientists of the developing world with those in the developed world so that research and technologies adapted to local requirements can be established ${ }^{6}$. It is hoped that Internet access might also reduce the 'brain drain', by connecting local investigators to the rest of the international scientific community and by allowing free and unlimited Internet-based interactions.

Some counter-arguments do, however, balance this optimism. First, Internet-based students using search engines are flooded with a huge number of answers and web sites from which they must choose, often without any clue about the relevance of the outcome of the search. As the journalist I. Ramonet wrote, "In thirty years, the world produced more information than for the previous 5000 years ... Although rare and costly for a long time, information started proliferating and certainly got cheaper and cheaper as its flow increased, but as a consequence, it became more and more polluted."7 (translated by J.-J.F.) In this respect, we think that only the expertise of informed scientists can filter the information and guide students to the best web sites and the most relevant material.

Second, most Internet-based immunology courses are not available in multiple languages, which limits their use to
English-speaking students and puts up an additional barrier to their use.

Third, the immediate needs of resourceconstrained countries are in the production and transmission of the following: technical knowledge, biotechnologies that have been validated in the field (such as cheap and robust diagnostic tools), drugs and vaccines. But in an Internet-based learning environment, the inherent practical training in immunology (for example, carrying out protein chromatography, enzymelinked immunosorbent assays (ELISAs), gel electrophoresis or PCR) that might drive students along the right track to develop simple and robust diagnostic tools, drugs or vaccines cannot be addressed. This type of training requires the physical presence of experienced teachers and the availability of laboratory equipment and reagents. In universities with low (or no) entrance fees, the large number of trainees is frequently the main bottleneck that prevents reasonable access to such material. This often leads to reuse of laboratory equipment, such as culture plates and pipette tips.

Last, in many poor countries, the quality of computer hardware and the level of access to the Internet are not yet sufficient to support online courses. Indeed, after their university lectures, students often rush to a cybercafé to hunt for additional documents. This lack of access to the Internet is highlighted by the fact that, by 2003, per 1000 inhabitants, there were 365 computer users in France, among whom 347 were Internet users, whereas in Africa, there were 14 computer users, all using the Internet (data obtained from GeoHive; see the Online links box). Computer use varies considerably from one country to another: for example, there were 70 users of computers and the Internet in South Africa (per 1000 inhabitants), 30 users of computers and the Internet in Paraguay and Georgia, and less than 10 for any country in the Sahel (which is the semi-arid border of the Sahara, extending from Senegal and Mauritania on the west coast of Africa, through Mali, Burkina Faso, Niger, northern Nigeria and Sudan, to Ethiopia on the east coast). This e-gap between the countries reflects their financial differences, bringing into question the efficiency of the Internet to solve the educational problems of developing countries. Interestingly, use of the Internet is greatest in the fastest developing regions (in Southeast Asia, Brazil, Chile, India, China, Mexico and South Africa, where there are 100 users of computers and the Internet per 1000 inhabitants), correlating the use of the Internet with human development. 
By simultaneously bringing together online users, the Internet is certainly the most unprecedented opportunity to improve, at low cost, the teaching deficit in developing countries. Because of its technological nature, however, this medium still cannot reach some isolated regions and cannot physically link teachers and students for practical workshops. This means that the need remains for more direct scientific interactions between researchers and health-care professionals in developed and developing countries, as discussed in the next section.

\section{Direct interactions between scientists} To improve the level of education and research in immunology in developing countries, there is a need to promote more sharing of knowledge with scientists and students from locations where computers and the Internet are not easily available. Conferences, workshops and summer courses are extremely popular in developed countries to promote direct communication between scientists. Now, on the information board in front of our office, ten meetings that are planned for upcoming months are asking for applicants, but none is to be held outside Europe or the United States. Are there similar local opportunities for our colleagues in developing countries? So far, only a few international courses are available to doctors, scientists and students from developing countries in their own regions. These include the International Course in Serological Diagnostic Techniques, which is held at the Biomedical Research and Training Institute (Harare, Zimbabwe) and the International Course for Clinical Immunology of Infectious Diseases \& Total Quality Management (Ismailia, Egypt) (ICCI-TQM; see the Online links box). Here, we describe three examples of different, nonvirtual approaches to immunology teaching in developing countries.

Teaching organized by small non-government associations: Universités du Monde. Created in 2001 by French immunologists, Universités du Monde (UDM; see the Online links box) is a non-government and non-profit association that organizes and promotes access to immunology summer courses for students and doctors from poor, non-English-speaking countries. These courses concentrate on the most up-to-date information about fundamental immunology and infectious diseases, with a focus on endemic diseases (BOX 1). UDM has organized summer schools focused on infectious diseases in French-speaking developing countries. For example, during a summer school in Burkina Faso, courses comprised an update on fundamental immunology and specific conferences and workshops on HIV/AIDS, malaria, and tuberculosis and other mycobacterial diseases. Seminars on

\section{Box 1 | UDM: summer school on infectious and emerging}

Universités du Monde (UDM) organized a summer school on infectious and emerging diseases for three weeks in Ouagadougou, Burkina Faso, in 2002. This involved 50 participants, including students in their second and third years of study at university, as well as pharmacists, doctors and university professors, from 9 west African countries: Benin, Burkina Faso, Central African Republic, Chad, Côte d'Ivoire, Democratic Republic of Congo, Gabon, Niger and Togo. Attendees followed a programme of courses, workshops, conferences and meetings on the immunology of infectious diseases. The objectives were the following: to set the first steps of a network between western Africa and Europe for research on infectious diseases; to create dynamic networks that included scientific, political, institutional and associative staff; and to allow future researchers to attend top-level courses and to exchange ideas about their own research practices and plans. The programme comprised the following: 20 lectures on fundamental immunology, viral diseases, malaria, and tuberculosis and other mycobacterial infections; 10 sessions of directed workshops; 3 public conferences for lay people (The Control of the HIV Epidemic in Africa, by F. Barré-Sinoussi; Prions, from Mad Cow to Man: Origin, Therapeutic Transmission and Therapies, by D. Dormont; and Meningitis in Western Africa, by P. Saliou); and 3 public debates (Ethics and Research; Towards North-South Research Networks; and Role of the Associative Area in Public Health). The summer school was held with the supervision of 19 advisers from Burkina Faso, Côte d'Ivoire, France and Germany. Financial and logistical partners were Aide et Action (France), Aventis Pasteur (France), Centre Muraz de Bobo-Dioulasso (Burkina Faso), Saint Camille Medical Centre of Ouagadougou (Burkina Faso), Centre National de la Recherche Scientifique (France), Ecoliers du Monde (France), Institute of France (France), Pasteur Institutes of Paris (France) and Abidjan (Côte d'Ivoire), Institut National de la Santé et de la Recherche Médicale (France), Aventis Foundation (Germany), University of Ouagadougou (Burkina Faso) and University of Tübingen (Germany).

prion diseases were also included, because African countries import large quantities of low-cost meat from Europe. In general, the summer courses last 3 weeks and comprise both theoretical courses and technical training for about 30 attendees, to update their theoretical and technical expertise on microbial, viral and parasitic diseases. Attendance and accommodation are free for the participants, with funding being provided by private sponsors, charities and institutional research organizations from France. In partnership with the French charity Aide et Action, UDM has also provided a course for primary school teachers in Burkina Faso to enable them to educate school children better about the modes of transmission of important infectious diseases.

Scientific training initiated by nongovernment organizations and relayed by institutions. Since 1977, the Committee for Scientific and Technical Collaboration with Vietnam (France) has organized a course in fundamental and applied immunology (covering cellular immunology, biochemistry of microbial antigens, virology and entomology) at the National Institute of Hygiene and Epidemiology (INHE), in Hanoi, Vietnam ${ }^{8}$. Under the initiative of immunologists from the Pasteur Institute in Paris, France, the original course was given in French and was specifically designed for the local attendees, who were scientists, doctors, pharmacists and veterinary surgeons. These trainees then became the scientific managers of the INHE and co-organized the course with the French partners in subsequent years. The course encompasses updates on fundamental immunology and practical workshops, with laboratory material that was initially brought in by the external advisors. In the 1980s, the first Vietnamese biotechnology products were developed, including an $\alpha$-foetoprotein-based kit for serodetection of liver cancer (which has a high incidence in Asia) and a functional factory for producing the BCG (Mycobacterium bovis bacillus Calmette-Guérin) vaccine scaled to fulfil Vietnamese needs. In 1990, as a result of these successes, new sources of funding (including funds provided by UNESCO, and the International Network of Pasteur Institutes and its sister institutes) became available. This funding supported more international workshops, which were held at the INHE and were focused on biomolecular techniques of pathogen identification, such as diagnosis of tuberculosis or subtyping of HIV isolates. This example shows that small initiatives in scientific training, which are then further 


\section{BOx 2 | WHO TDR immunology training courses}

The World Health Organization (WHO) Special Programme for Research and Training in Tropical Diseases (TDR) provides immunology training courses. So far, these have consisted of two advanced courses of eight weeks duration, entitled The Applications of Immunology, Biotechnology and Vaccinology to the Control of Infectious Diseases. These courses were organized at the WHO Centre in Lausanne, Switzerland, in 1999. Thirteen professionals participated in a course given in French (from May to June), and 20 professionals participated in a course given in English (from September to October). The participants came from Bolivia, Burundi, Cuba, Guinea, Laos, Mali, Mauritania, Morocco, Niger, Senegal, Togo, Vietnam, Brazil, Egypt, Ethiopia, Guatemala, India, Kenya, Myanmar, Nigeria, Sri Lanka, Sudan, Thailand and Uganda. An advanced refresher course of three weeks duration, entitled Immunology, Biotechnology and Vaccinology Applied to Infectious Diseases, was also organized at the National Institute of Virology, in Pune, India, in December 1999. Such continuing education courses are mainly addressed to professionals from a given area who have previously attended a core course in Switzerland. This particular course was attended by 21 professionals from India, Iran, Mongolia, Myanmar, Sri Lanka, Thailand and Vietnam. In 2000, an advanced training course of eight weeks duration on the same topics was again organized at the WHO centre in Lausanne. This course was attended by 18 professionals from Bangladesh, Bhutan, Brazil, China, Colombia, Cuba, Egypt, Ethiopia, Ghana, Kenya, Myanmar, Nepal, Nigeria, Sri Lanka, Sudan, Thailand, Uganda and Vietnam. An advanced refresher course of three weeks duration, entitled Immunology, Vaccinology and Biotechnology Applied to Infectious Diseases, was organized again in December 2000, and it was held at the National Institute of Health, in Maputo, Mozambique. The 23 participants (of whom 20 had previously attended a core course in Switzerland) were from Cameroon, Ethiopia, Ghana, Kenya, Mozambique, Nigeria, Sudan, Tanzania, Zambia and Zimbabwe. Fifty-eight facilitators, who were experts in their fields, participated in the teaching of this course. The facilitators came from Canada, France, India, Italy, Korea, Mozambique, the Netherlands, Nigeria, South Africa, Switzerland, the United Kingdom and Zimbabwe.

relayed by institutional collaborations, can build the foundations for long-lasting development, resulting in strong scientific achievements and in training of health representatives for developing countries.

Annual international courses organized by institutions. These courses in immunology or infectious diseases are organized by large biomedical research institutions from rich countries, which finance and supervise the courses and check the content of the lectures. Initiatives such as these include the WHO Special Programme for Research and Training in Tropical Diseases (TDR; see the Online links box) (BOX 2) - in which half of each programme takes place in Switzerland and half in developing countries - and the international courses that are organized by the Pasteur Institute (see Pasteur Institute international courses in the Online links box).

These institutional collaborations have long experience in promoting immunology workshops and courses in English-speaking countries, and sometimes in French-speaking or Spanish-speaking countries, on most continents. The well-established TDR course that is offered annually by the WHO is focused on the immunology of tropical disease. The course is designed for a limited number of attendees and lasts several weeks (BOX 2). Its structure consists of a core immunology course, which is held in Lausanne, Switzerland, followed by applied workshops, which are held in the attendees' laboratories. The workshops take place either in English-speaking or Frenchspeaking countries, under the supervision of a board that comprises both international and local scientists. The regular increase in the number of applicants and the diversity of the countries where these courses have taken place indicate the efficiency of this important tool for the teaching of immunology. Financing for this initiative comes mainly from the WHO, the Swiss Agency for Development and Cooperation and the International Union of Immunological Societies (see the Online links box).

Direct interactions with scientists together with online learning. Despite the high quality of teaching, these international courses have two disadvantages compared with the use of Internet-based information to teach immunology: they are expensive, and they address only a restricted audience. So, should we choose quality over quantity in immunology teaching? Although, in rich countries, the answer to the question is yes, should this also apply to developing countries, which have huge needs for education and training? We think that the answer is yes but that combining both modes of teaching is the most effective way forward.

\section{Future directions}

Developing countries need to develop their own science rather than just transfer technologies that are inappropriate to the location. In the developing world, building new research laboratories for the study of infectious diseases can and must take place at a local level, and these laboratories must employ immunologists who are trained by the national universities. The global scientific community needs to make relevant, novel information and technical knowledge available to these immunologists to help them to accomplish their research programmes. The requirements of these immunologists are so great that even a small input will make a large difference. If Internet access and content can be improved at little expense, then this will improve the effectiveness of university courses for undergraduates. The establishment and evaluation of specific research programmes will still require frequent and direct exchanges between small groups of specialized scientists, as occurs in the developed world at present. Although initially dependent on outside funding, the success and perpetuation of such programmes should help countries to achieve financial autonomy. Indeed, as Kofi Annan, Secretary-General of the United Nations, said, "A future of sustainable development begins with safeguarding the health of every child"', and this is the future challenge for those already sharing scientific knowledge with the aim of improving the health of the poorest.

Jean-Jacques Fournié and Frédérique Gaits are at the Département Oncogénèse \& Signalisation dans les Cellules Hématopoiétiques,

Institut National de la Santé et de la Recherche Médicale, Unité 563, Centre de Physiopathologie de Toulouse Purpan, Pavillon Lefebvre, BP3028 CHU Purpan, Toulouse 31024, France.

Marc Bonneville is at the Institut National de la Santé et de la Recherche Médicale, Unité 601, 9 Quai Moncousu, Nantes 44035, France.

Correspondence to J.-J.F. e-mail: fournie@toulouse.inserm.fr

doi:10.1038/nri1709

Published online 20 September 2005

1. United Nations Development Programme. in Human Development Report 2003 237-339 (Oxford Univ. Press, New York, 2003).

2. Joint United Nations Programme on HIV/AIDS \& World Health Organization. AIDS Epidemic Update: 2004 (Joint United Nations Programme on HIV/AIDS, Geneva, 2004).

3. Bollag, B. Amélioration de l'Enseignement Supérieur en Afrique Sub-Saharienne: Ce Qui Marche! (World Bank, Washington D.C., 2004) (in French).

4. Sibanda, E. N. Research and clinical aspects of immunology in Africa. Curr. Opin. Immunol. 13, 528-532 (2001).

5. Huitema, C. Et Dieu Créa l'Internet (Eyrolles, Paris, 1995) (in French).

6. Winter, G. L'impatience des Pauvres (Presses Universitaires de France, Paris, 2002) (in French). 
7. Ramonet, I. in La Tyrannie de la Communication 198 (Galilée, Paris, 1999) (in French).

8. Simon-Cortés, N. \& Teissonnière, A. Viet-Nam, une coopération exemplaire. Henri Van Regemorter (1925-2002). Parcours d'un militant (l'Harmattan, Paris, 2004) (in French).

9. Annan, K. A. A future of sustainable development begins with safeguarding the health of every child. Food Nutr. Bull. 25, S3-S4 (2004).

10. L'État du Monde 2003 (La Découverte, Paris, 2002) (in French).

11. Center for International Earth Science Information Network. Gridded Population of the World [online], <http://sedac.ciesin.columbia.edu/gpw> (2000).

Acknowledgements

The authors acknowledge support from the Institut Nationa de la Santé et de la Recherche Médicale (France) and the TB Vaccine Cluster (European Union). The work by J.-J.F. and M.B. was also financed by the European Commission, within the 6th Framework Programme. The statements in this publication are the views of the authors and do not necessarily reflect the policies or views of the European Commission, which is not liable for the use made of such information. The authors dedicate this article to the immunologists all over the world who recycle their single-use labware.

Competing interests statement

The authors declare no competing financial interests.

\section{(9) Online links}

DATABASES

The following terms in this article are linked online to:

Infectious disease information:

http://www.cdc.gov/ncidod/diseases/index.htm

AIDS | malaria | meningitis | SARS | tuberculosis

\section{FURTHER INFORMATION}

Armauer Hansen Research Institute:

http://www.telecom.net.et/ ahri

AVERT: http://www.avert.org/aidschina.htm

Braintrack University Index:

http://www.braintrack.com

GeoHive: http://www.geohive.com/global
Global Atlas of Infectious Diseases:

http://globalatlas.who.int/globalatlas/InteractiveMapping/rmm/ default.asp

HINARI: http://www.healthinternetwork.org

HIVAN: http://www.hivan.org.za

ICCI-TQM: http://www.icci-tam.net

International Association of Universities:

http://www.unesco.org/iau

International Union of Immunological Societies:

http://www.iuisonline.org

Oswaldo Cruz Institute:

http://www.dbbm.fiocruz.br

Pasteur Institute international courses:

http://www.pasteur.fr/actu/presse/press/RIIP/Education.htm

Swiss Agency for Development and Cooperation:

http://www.sdc.admin.ch/index.php?userhash?31195595\&na

$\mathrm{VID}=1 \& \mid=\mathrm{e}$

TDR: http://www.who.int/tdr/research

UDM: http://www.univ-du-monde.org

UNESCO: http://portal.unesco.org/

Universities Worldwide: http://univ.cc/index.htm

WHO: http://www.who.int/en

World Bank: http://www.worldbank.org

Access to this interactive links box is free online. 